\title{
Remote sensing and climate data as a key for understanding fasciolosis transmission in the Andes: review and update of an ongoing interdisciplinary project
}

\author{
Màrius V. Fuentes \\ Departament de Parasitologia, Facultat de Farmàcia, Universitat de València, València, Spain
}

\begin{abstract}
Fasciolosis caused by Fasciola hepatica in various South American countries located on the slopes of the Andes has been recognized as an important public health problem. However, the importance of this zoonotic hepatic parasite was neglected until the last decade. Countries such as Peru and Bolivia are considered to be hyperendemic areas for human and animal fasciolosis, and other countries such as Chile, Ecuador, Colombia and Venezuela are also affected. At the beginning of the 1990s a multidisciplinary project was launched with the aim to shed light on the problems related to this parasitic disease in the Northern Bolivian Altiplano. A few years later, a geographic information system (GIS) was incorporated into this multidisciplinary project analysing the epidemiology of human and animal fasciolosis in this South American Andean region. Various GIS projects were developed in some Andean regions using climatic data, climatic forecast indices and remote sensing data. Step by step, all these GIS projects concerning the forecast of the fasciolosis transmission risk in the Andean mountain range were revised and in some cases updated taking into account new data. The first of these projects was developed on a regional scale for the central Chilean regions and the proposed model was validated on a local scale in the Northern Bolivian Altiplano. This validated mixed model, based on both fasciolosis climatic forecast indices and normalized difference vegetation index values from Advanced Very High Resolution Radiometer satellite sensor, was extrapolated to other human and/or animal endemic areas of Peru and Ecuador. The resulting fasciolosis risk maps make it possible to show the known human endemic areas of, mainly, the Peruvian Altiplano, Cajamarca and Mantaro Peruvian valleys, and some valleys of the Ecuadorian Cotopaxi province. Nevertheless, more climate and remote sensing data, as well as more accurate epidemiological reports, have to be incorporated into these GIS projects, which should be considered the key in understanding fasciolosis transmission in the Andes.
\end{abstract}

Keywords: fasciolosis, geographic information system, climatic forecast indices, remote sensing data, Andes.

\section{Introduction}

Fasciola hepatica and F. gigantica are the two trematodes which cause human and animal fascioliosis. These hepatic helminth parasites are present around the world infecting a great variety of mammals as definitive hosts, but using only some species

\footnotetext{
Corresponding author:

Màrius V. Fuentes

Departament de Parasitologia, Facultat de Farmàcia

Universitat de València

Avinguda de Vicent Andrés Estellés s/n

46100 Burjassot, València, Spain

Tel. +3496 3544298; Fax +34963544769

E-mail: mario.v.fuentes@uv.es
}

of snails (belonging to the Lymnaeidae family) which act as their sole intermediate host. The presence of this particular species of snail is the most important factor which determines the possibility to complete the life cycle of this zoonotic disease. In both Fasciola species the cycle includes various free environmental stages, such as embryonation of eggs, taking between 10 to 15 days to reach the miracidium stage; the free single-tailed cercaria which encysts on aquatic plants, grass or develops as a free water circulating metacercaria - the infestant form for the definitive host. F. hepatica is found in the five continents, however, F. gigantica is primarily distributed in tropical regions excluding America.

These liver fluke species are well known owing to 
their worldwide veterinary importance.

Nevertheless, the review by Chen and Mott (1990) was the first global study considering fasciolosis as a human disease which has to be considered a serious public health problem in some endemic areas, including Andean countries, Iran, northern Africa, and western Europe.

Until the last decade, the importance of this zoonotic parasite had been neglected in South American countries, and human infection by $F$. hepatica was not regarded as an important health problem. However, the countries located on the slopes of the Andes, i.e. Peru, Bolivia and Chile are the most severely affected by this trematode (Alcaino, 1990), though areas of Ecuador, Colombia and Venezuela are also affected. The Northern Altiplano, between Bolivia and Peru, is considered to be a hyperendemic zone for both humans and animals, while the central regions of Chile are hyperendemic in terms of domestic cattle (Knoblock et al., 1985; Alcaino et al., 1993; Apt et al., 1993).

At the beginning of the 1990s the multidisciplinary fasciolosis research team of Universitat de València, Spain, headed by Prof. Mas-Coma and composed of nine full professors and more than ten young but experienced researchers, launched a project with the aim to shed light on the problems related to human and animal fasciolosis in the Northern Bolivian Altiplano. For the last fifteen years this team has been investigating fascioliosis transmission in this hyperendemic area situated at very high altitude $(3800-4100 \mathrm{~m}$ a.s.1), and has, step by step, been scrutinizing every single factor which might take part in the completion of the life cycle of $F$. hepatica. This successful multidisciplinary project has focused on biotic and abiotic factors (geographical, climatic, anthropological, etc.) which might play a role in the transmission of human and animal fasciolosis in the Altiplano endemic area. The complete life cycle has been developed at laboratory level, and the transmission suitability and capacity of both the intermediate and the definitive hosts have been determined (MasComa et al., 1999a, 2003, 2005 and Mas-Coma,
2005).

The endemic areas of human and animal fasciolosis in the Andean region present a very wide spectrum of epidemiological characteristics related to the diversity of environments, with a great variety of climatic and altitudinal conditions. Their different abiotic (i.e. climate, hydrology, geomorphology, landscape, etc.) and biotic factors (i.e. vegetation, fauna, etc.) emphasize the need for individualised studies. In this context, and with the aim to modelize fasciolosis transmission, a geographic information system (GIS) was incorporated into the multidisciplinary project at the end of the 1990s analysing the epidemiology of human and animal fasciolosis in this South American Andean region.

\section{Climatic forecast indices}

Climatic factors such as air temperature, rainfall and potential evapotranspiration affect the incidence of mammals (definitive hosts) as well as the population dynamics of the snails (intermediate hosts), and the free-living stages of F. hepatica, mainly eggs, and metacercariae. In this context, some climatic studies were carried out mainly in Europe (Ollerenshaw, 1959, 1971a,b, 1973, 1974; Ollerenshaw and Rowlands, 1959; Ollerenshaw and Smith, 1969; Ross, 1970, 1978; Gettinby et al., 1974; Leimbacher, 1978), in the southern states of the USA (Malone et al., 1987; Malone and Zukowski, 1992) and in the east of Africa (Malone et al., 1998; Yilma and Malone, 1998). Various climatic forecast indices were developed with the aim to predict the animal fasciolosis transmission risk: the Stormont 'wet day' index (Ross, 1970) and the temperature model (Gettinby et al., 1974), both being rather limited as they are based on one climatic factor only; and the more complete and more frequently used, Mt index (Ollerenshaw and Rowlands, 1959) and the Water-budget-based system (Wb-bs) index (Malone et al., 1987).

Taking into account the positive results obtained by the aforementioned climatic forecast indices, 
Fuentes et al. (1999) applied, for the first time, the $\mathrm{Mt}$ and the Wb-bs indices to forecast the fasciolosis transmission risk in humans and at very high altitude in the Northern Bolivian Altiplano. This study was based on the use of a 38-year period climate database, with daily data collected at five observing stations from the endemic area and correlated with the existing human prevalence database (Esteban et al., 1999). However, neither of the two indices explained the differences between the human prevalence found around each climatic station analysed, when the same formulas and climatic variables that were proposed or modified by the authors, were used (see Ollerenshaw, 1971a, 1973 for the Mt index and Malone et al., 1998 for the Wb-bs index):

$$
\mathrm{Mt}=\mathrm{n}(\mathrm{R}-\mathrm{P}+125) / 25
$$

where Mt is expressed in $\mathrm{mm}, \mathrm{n}$ is the number of rainy days, $\mathrm{R}$ expresses the rainfall in inches, $\mathrm{P}$ reflects the potential transpiration (after Penman, 1948) in inches, and for the calculation only the months with a mean temperature higher than $10^{\circ} \mathrm{C}$ are considered.

Wb-bs $=$ (GDD $x$ days in month), IF [R-(PET $x$ $0.8)]>0+($ GDD $\times 6)[(\mathrm{R}-\mathrm{PET}) / 25], \mathrm{IF}(\mathrm{R}-\mathrm{PET})>0$

where $\mathrm{R}$ expresses rainfall, PET is the potential evapotranspiration (calculated by the modified
Penman, 1948 method) and GDD is the average annual mean temperature minus the base development temperature for the liver fluke.

Consequently, the authors analysed the complete climatic dataset and created a climadiagram (Walter et al., 1975) for each station, in which the dry and the wet period are delimited. Nevertheless, the most important success of Fuentes et al. (1999) concerning the climadiagram was the introduction of the Aridity index $(r)$ originally proposed by Schreiber (1981) to adjust both the high altitude and the low latitude. In these new climadiagrams the Aridity index, instead of temperature, and the rainfall curves delimit the real dry and wet periods, showing a new conception of climatic dynamics (Fig. 1). The authors extended this correction to the calculation of the climatic forecast indices and introduced some changes: the replacement of PET by $r$ and the use of a corrected mean monthly temperature which changes according to altitude. Consequently, the modified $\mathrm{Wb}-\mathrm{bs}$ index (Fig. 2) is able to explain $93 \%$ of human and more than $99 \%$ of cattle fasciolosis prevalence and allows the authors to categorize the studied zones as low risk, moderate risk or high risk areas for the fasciolosis transmission to humans and other mammals. These authors recommend the Mt index not to be used for the Andean region. However, the aforementioned results were obtained by taking into account only four of the five initial climatic stations analysed. The authors omitted the station of Huarina since

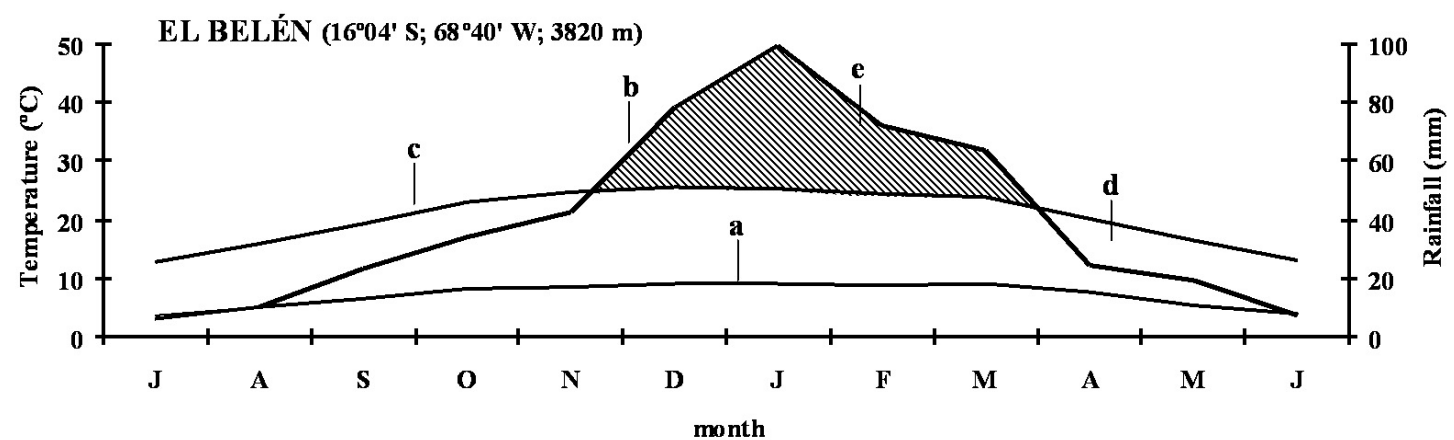

Fig. 1. Climadiagram for the climatic station of El Belén, Northern Bolivian Altiplano. $a=$ mean monthly temperature; $\mathrm{b}=$ mean monthly precipitation; $\mathrm{c}=$ aridity index; $\mathrm{d}=$ dry period; $\mathrm{e}=$ wet period. 


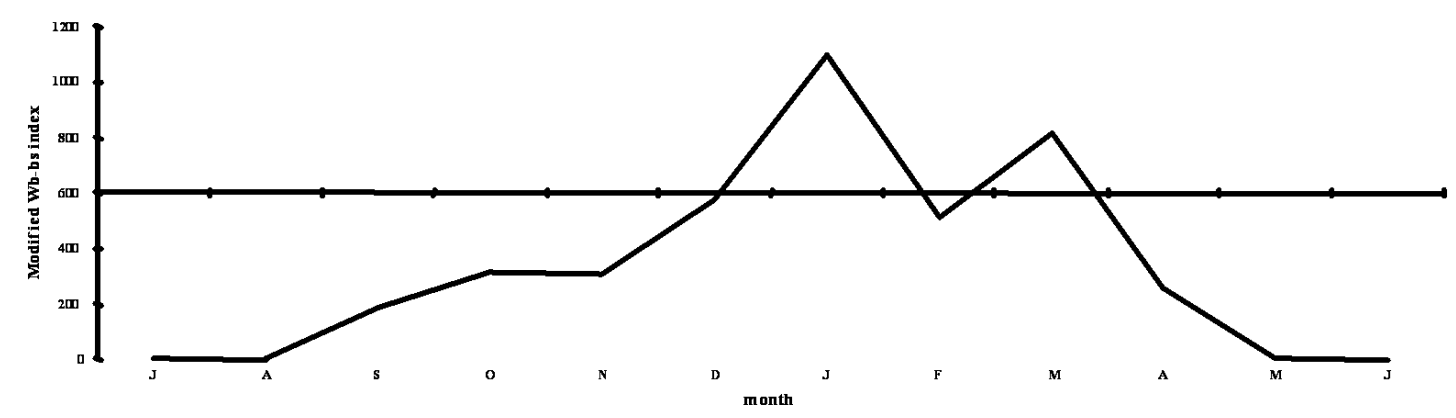

Fig. 2. Yearly evolution of the monthly values of the Wb-bs fasciolosis forecast index for the climatic station of Huacullani, Northern Bolivian Altiplano.

there are no Lymnaeids present in this zone, but they were not able to explain neither the snail and nor transmission absence using only fasciolosis climatic forecast indices.

A similar study was developed by Fuentes and Malone (1999) using a total of 15 observing stations and the calculation of the Wb-bs index to forecast animal fasciolosis transmission in the seven regions located in central Chile. The introduction of a new modification of the original index became necessary. In this case, after the adjustment of the temperatures required for life cycle progression, the index explained $79 \%$ of animal fasciolosis transmission in the seven regions studied, but, once again, one of the extreme prevalence (Schenome and Rojas, $1988)$, i.e. the very high prevalence in the VIIth Region $(90 \%)$, could not be completely explained using only climatic data.

\section{Remote sensing data}

Remote sensing data was used for the first time by Malone and collaborators as a new tool to control and understand the transmission of human snailborne infections. Malone et al. (1997) for Schistosoma mansoni and S. haematobium in the Nile Delta in Egypt and Bavia et al. (1999) for S. mansoni in the state of Bahia in Brazil, developed a GIS model using various satellite sources to obtain normalized difference vegetation index (NDVI) and Tmax data which - together with other factors - were correlated to schistosomiasis transmission in the aforementioned human schistosomiasis endemic areas. Malone et al. (1998) and Yilma and Malone (1998) developed a GIS model to forecast transmission and control animal fasciolosis in the east of Africa using climate as well as remote sensing data.

Following the good results obtained using remote sensing data as a complementary tool of the climatic indices, Fuentes et al. (2001) used NDVI data to study human fasciolosis in the Andean region for the first time. However, NDVI values, ranging from -1 to +1 and showing the response of vegetation to rainfall, had previously been applied by Fuentes and Malone (1999) to forecast fasciolosis transmission in South America. These authors had developed a forecast system for animal fasciolosis transmission in central Chile as a complement of the above-mentioned climatic indices.

In both projects the images used to provide remote sensing data were downloaded from the EROS data center (Sioux Falls, SD) Global land 1 km (http:// edcdaac.usgs.gov/1KM/1 kmhomepage.html) which provides free access to image archives for scientific purposes. The dataset was composed of a total of 36 10-day (dekade) composite images covering the endemic areas analysed and corresponding to a complete year period between 1992 and 1993. The dataset archives are designed to provide cloud-free quality images on a global scale derived from the Advanced Very High Resolution Radiometer 
(AVHRR) sensor on board the National Oceanic and Atmospheric Administration (NOAA) environmental satellite series. Monthly NDVI data was obtained at a resolution of $1 \mathrm{~km}$ using Erdas Imagine software. The same software was used to create annual mean NDVI images and to obtain NDVI values at a regional level in Central Chile (Fuentes and Malone, 1999) or for circular 10-km diameter areas in the Northern Bolivian Altiplano (Fuentes et al., 2001). ArcView GIS and the Spatial Analyst extension were the software chosen to display the various layers analysed and to create the fasciolosis transmission risk map for both areas.

The project developed at regional level in Central Chile by Fuentes and Malone (1999) made it possible to improve the aforementioned climatic model. The mean NDVI values as well as the majority NDVI classes present in each region showed a strong positive correlation with the fasciolosis prevalence and a negative correlation between the minority NDVI classes and the prevalence of the disease. These results allowed the authors to establish a multiple correlation between the high NDVI values and the prevalence (Fig. 3), and to create a fasciolosis risk map at regional level. However, and in spite of the good results, the model could not completely explain animal fasciolosis transmission in each region. The authors proposed the validation of the methodology used providing fasciolosis prevalence data at local level.

Human fasciolosis prevalence data at local level was reported by Esteban et al. (1999) and MasComa et al. (1999b) for the Northern Bolivian Altiplano. These data allowed Fuentes et al. (2001) to validate the central Chilean model in the Northern Bolivian Altiplano. A mapping and a prediction model for human fasciolosis transmission was created at a local scale for this Andean endemic region located at very high altitude. The model resulted in the creation of a fasciolosis transmission risk map derived from NDVI values showing no risk, low or moderate risk, and high risk areas (Fig. 4). The high level of correspondence obtained between human fasciolosis prevalence and NDVI predicted ranges were contrasted with results from climatic forecast indices. As an example, the locality of Huatajata was included in the no risk area, while Fuentes et al. (1999) predicted for this location a high transmission risk through climate forecast. Moreover, some areas where human and animal fasciolosis had not been detected before 2001, but classified by the model as low or moderate risk areas, such as the corridor of Jesús de Machaca, the presence of the snail intermediate host and the liver fluke were detected fairly recently (Mas-Coma and Anglés, per-

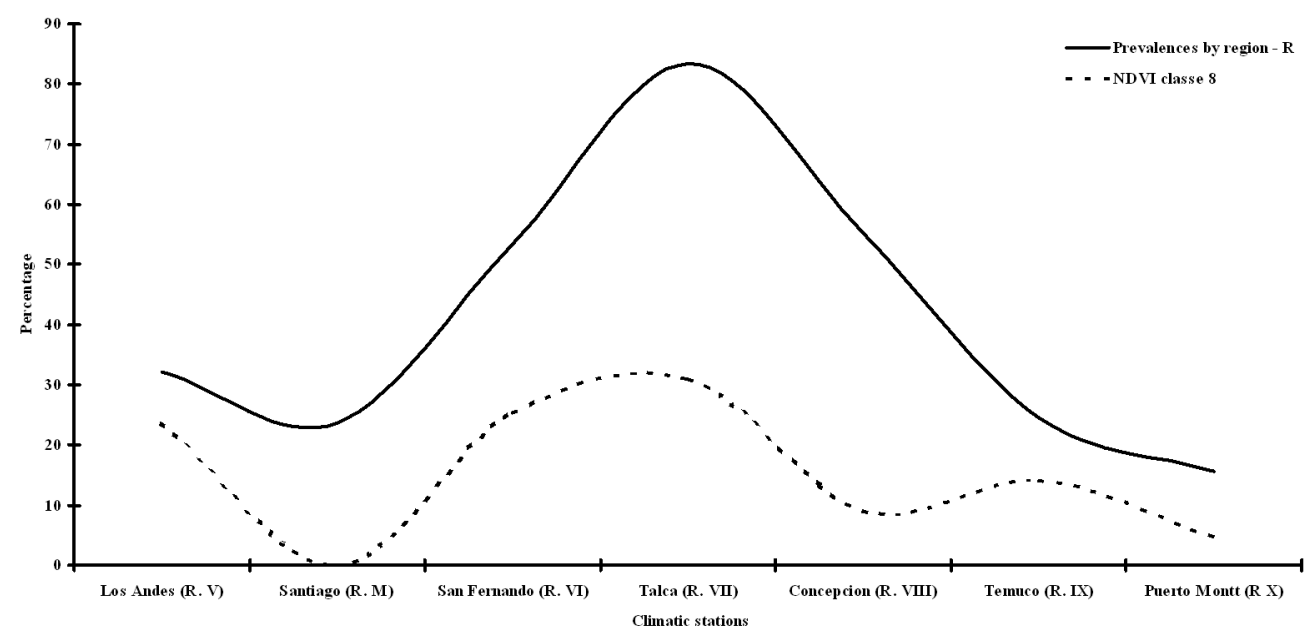

Fig. 3. Relation between fasciolosis prevalence and values of NDVI class $8(0.50-0.59)$ in central Chilean regions. 


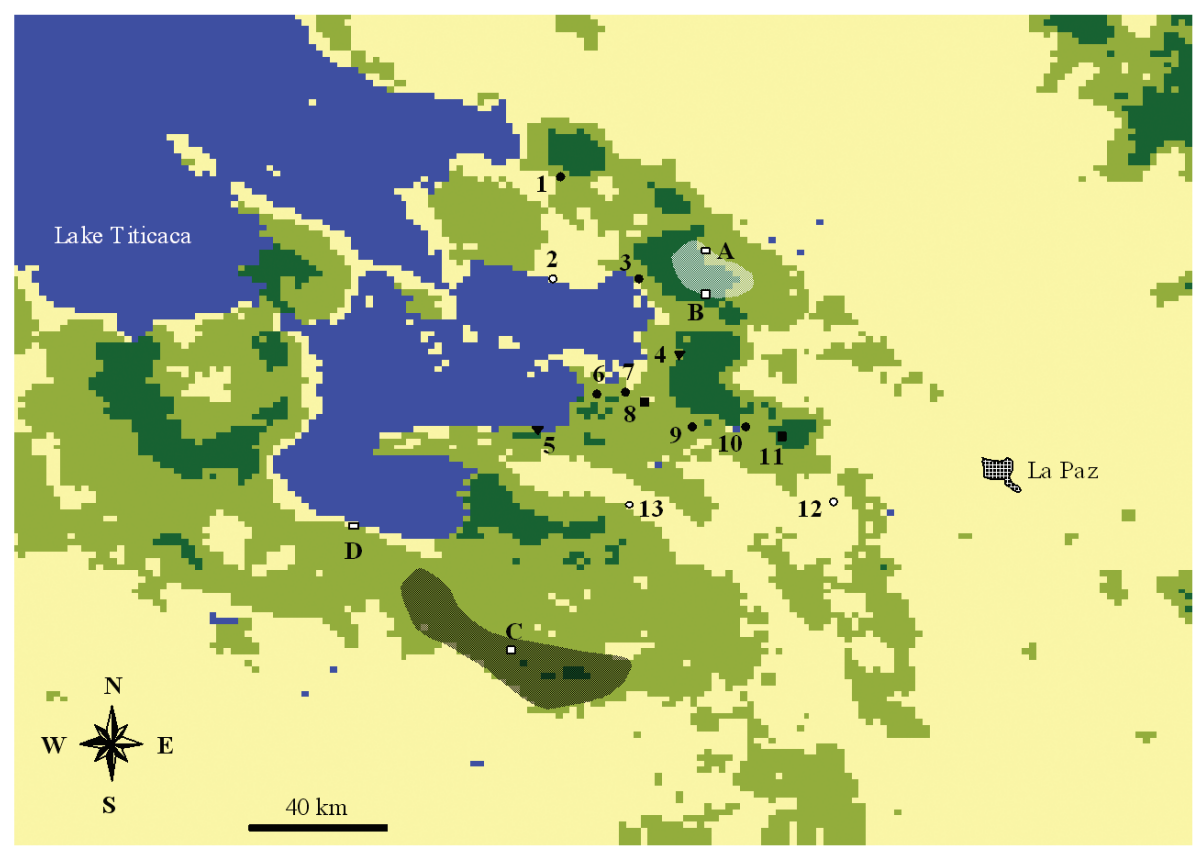

Fig. 4. Fasciolosis transmission risk map of the Northern Bolivian Altiplano human endemic area derived from NDVI values: blue, water; yellow, no risk; light green, low or moderate risk; dark green, high risk. Legend: $\bigcirc$ localities in which the parasite was not detected in humans; $\bullet$ localities with low prevalences $(<10 \%)$; localities with moderate prevalences $(10-20 \%)$; $\boldsymbol{\nabla}$ localities with high prevalence (>20\%); $\square$ altiplano corridors lacking lymnaeids: A, Kerani; B, Peñas; C, Jesús de Machaca; D, Desaguadero. White shaded area, corridor of Peñas; dark shaded area, corridor of Jesús de Machaca. Reproduced with kind permission from Acta Trop 79, 87-95, 2001.

sonal communication). Consequently, NDVI data maps have become a useful data component in longterm efforts to develop a comprehensive GIS control programme model that accurately fits real epidemiological and transmission situations of human fasciolosis in high altitude endemic areas in Andean countries (Fuentes et al., 2001).

\section{The Minimum Medical GIS Database (MMDb)}

The first meeting of the GNOSIS (GIS Network On Snail-borne Infections with special reference to Schistosomiasis) research group (sponsored by the Rockefeller Foundation) took place in Bellagio, Italy, in April 2000. As one of the most important goals of this team residency, and with the aim to use compatible GIS formats, software, methods and data resources, a minimum medical GIS database (MMDb) was estab- lished (Malone et al., 2001). For each region studied a particular MMDb was to be prepared, including georeferenced datalayers, relevant medical data concerning epidemiology of the disease, complete public access environmental data, climate, remote sensing sensor, soil types, land use data, etc. At present, $\mathrm{MMDb}$ for the IGAD-Nile Basin Africa, West Africa, Asia and South America are available at the GNOSIS group website (http://www.gnosisgis.org/).

However, while the South America MMDb is being prepared, and taking into account the particularities of human and animal fasciolosis, based on the aforementioned results concerning this disease in the Andes, Fuentes (2004) proposed the basis for the development of a GIS for conducting an epidemiological control programme for zoonotic fasciolosis in the Andes (Fig. 5). The GIS project is to be based on parasitological data concerning parasite forms as well as intermediate and definitive hosts, the most important 


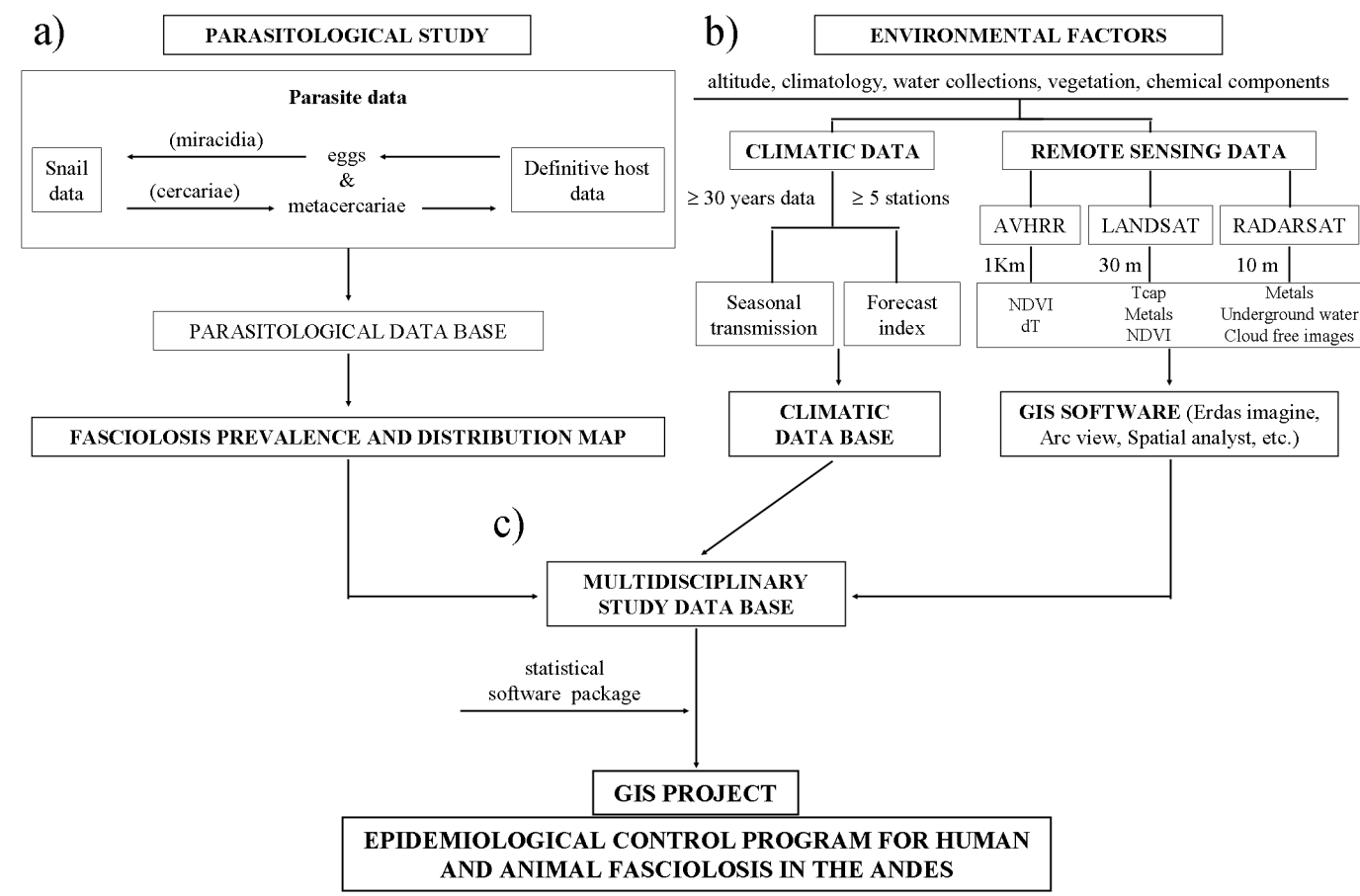

Fig. 5. Diagram presenting the GIS model for epidemiological control program for zoonotic fasciolosis in the Andes. Reproduced with kind permission from Parasitol Latinoam 59, 51-55, 2004.

environmental factors which directly influence the prevalence and transmission of fasciolosis, including climatic and remote sensing parameters obtained from terrestrial stations and satellite images, respectively.

\section{The Andean fasciolosis GIS model}

Based on the recommendations of Malone et al. (2001) and following the proposal of Fuentes (2004), Fuentes et al. (2004, 2005) developed a GIS model for zoonotic fasciolosis risk assessment in the South American Andean region which allows the identification of areas requiring the implementation of control activities through the classification of the degree of transmission risk for this hepatic disease. This model, based on the results obtained by Fuentes et al. $(1999,2001)$ in the Northern Bolivian Altiplano, also includes the calculation of the Wb-bs index accumulated values (Fig. 6) and provides a more accurate delimi- tation of the fasciolosis transmission risk period. This previously validated and now reinforced model was extrapolated to other Andean endemic areas on a local scale. Thus, this GIS, mainly based on the calculation of fasciolosis forecast indices and monthly NDVI values, made it possible to develop a spatial and temporal epidemiological model to map the potential fasciolosis transmission risk for the Northern Bolivian and Peruvian Altiplanos, Cajamarca and Mantaro Peruvian valleys, and the Ecuadorian provinces of Azuay, Cotopaxi and Imbabura (Fig. 7). Besides, as the fasciolosis transmission risk was classified into low, moderate and high risk for each studied region, the areas requiring the implementation of control activities were identified.

The Andean Altiplano model: climatic forecast indices predict a high transmission risk period from October until May (Fig. 6A), and the transmission risk map (Fig. 7A) shows the previously known endemic areas in the Northern Bolivian Altiplano 

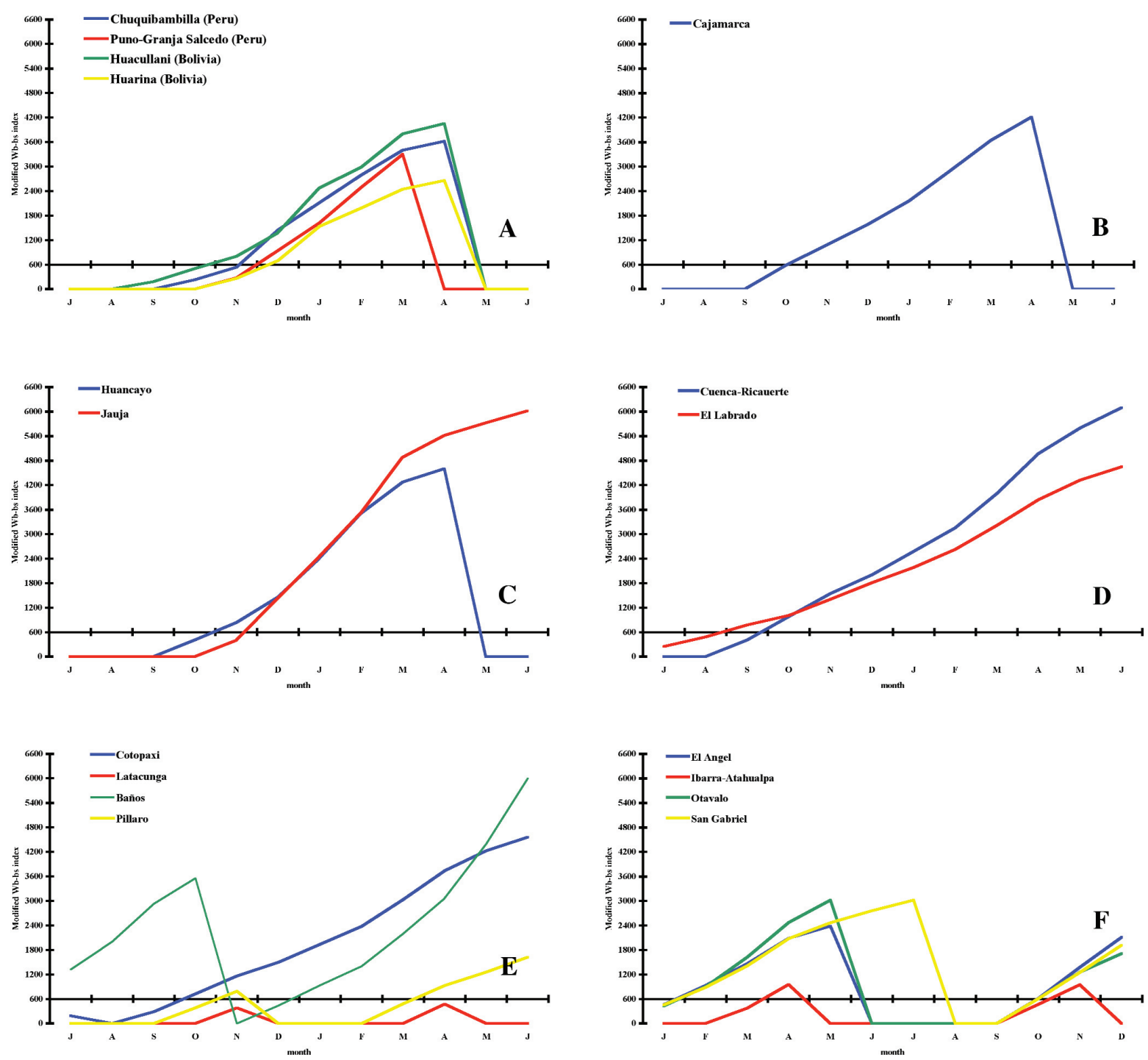

Fig. 6. Water-budget based (Wb-bs index accumulated values) for: A) the Altiplano region, B) Cajamarca valley, C) Mantaro valley, D) Azuay province, E) Cotopaxi province, and F) Imbabura province. Reproduced with kind permission from Parassitologia 47, 151-156, 2005.

and in the Asillo irrigation area, but also includes the zone located around the Titicaca Lake as a potential endemic area which has to be taken into account epidemiologically.

The Andean Valley model: this second model predicts the same high transmission risk period as in the Altiplano area, from October to May (Fig. 6B,
C) and the transmission risk map (Fig. 7B, C) shows the high risk zones which overlap with the known endemic areas of two valleys.

The Ecuadorian Andean Regions model: the third model delimits the high transmission risk period from October to June in various Ecuadorian Andean valleys (Fig. 6D, E, F), and the risk map 

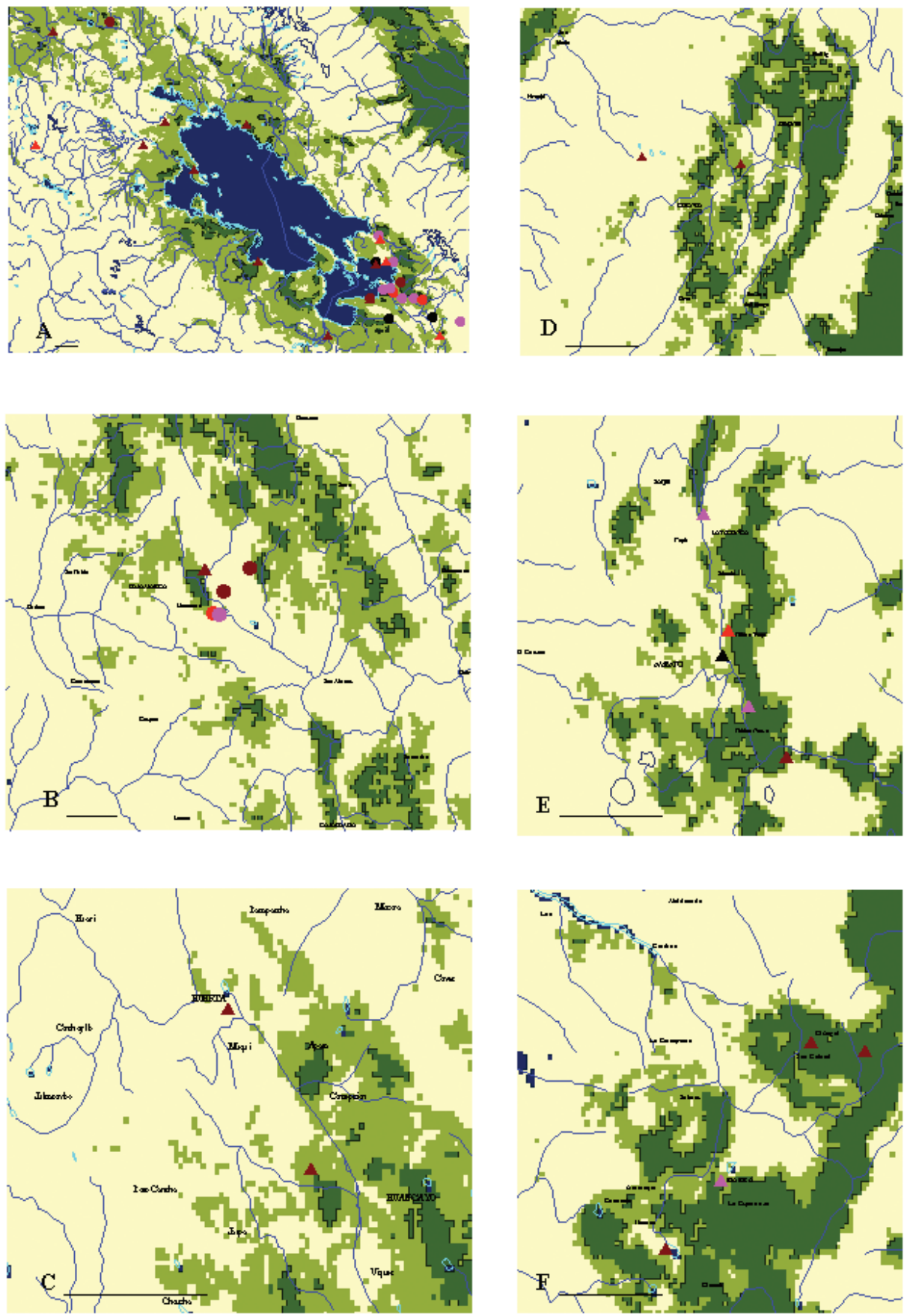

Fig. 7. Fasciolosis risk map for: A) the Altiplano region, B) Cajamarca valley, C) Mantaro valley, D) Azuay province, E) Cotopaxi province, F) Imbabura province. Blue, water; yellow, no risk; light green, low or moderate risk; dark green, high risk. Fasciolosis prevalence values from epidemiological surveys: $\Delta$, no fasciolosis; $\mathbf{\Delta}$ low prevalence $(<10 \%)$; $\mathbf{\Delta}$ moderate prevalence $(10-20 \%), \mathbf{\Delta}$, high prevalence $(>20 \%)$. Values of climatic indices: •, no fasciolosis risk; $\bullet$, low fasciolosis risk; $\bullet$, moderate fasciolosis risk; $\bullet$, high fasciolosis risk. Scale bar $=25 \mathrm{~km}$. Reproduced with kind permission from Parassitologia 47, 151-156, 2005. 
depicts the irregularity of the potential transmission in the three provinces (Fig. 7D, E, F).

This mixed model forecasts both the temporal and the spatial fasciolosis transmission risk in the endemic areas located in the Andean chain using climatic forecast indices and NDVI values, respectively. However, only the Northern Bolivian Altiplano model has been completely validated with human and animal fasciolosis prevalences, which correlate, at the same time, with the presence of appropriate snail intermediate hosts. Moreover, the model corresponding to the Peruvian Altiplano, specifically the Asillo irrigation area, and the model for some parts of the Cajamarca and Mantaro valleys, have been partially validated. Nevertheless, none of the three Ecuadorian provinces analysed has been validated, except the locality of Cuturiví Grande, Cotopaxi province, because reports of human and animal prevalences as well as the presence of suitable Lymaneids do not exist so far. In the case of Cuturiví Grande, Trueba et al. (2000), by means of immunological surveys, found a human fasciolosis prevalence of $6 \%$ in 1999 for this locality, where the mixed model had predicted a medium, respectively, a high transmission risk of $F$. hepatica.

\section{Future fasciolosis GIS projects}

The GIS models reviewed here make it possible to precisely delimit the spatio-temporal risk of fasciolosis in the endemic areas of the Andean mountain range. Nevertheless, existing and new epidemiological data as well as additional environmental factors will have to be taken into account.

Each of the environmental factors involved in transmission of fasciolosis will be included in the GIS project as new and compatible layers. In this sense, new remote sensing serial data has to be incorporated: Tmax, temperature difference and new NDVI data from low resolution satellite imagery, such as AVHRR sensor of the NOAA satellite and Modis sensor of the Terra satellite, and from medium and high resolution satellite imagery, such as Landsat and Spot satellites. Moreover, other low resolution non-serial data such as the digital elevation model, land cover and land use from the US Geological Survey (USGS) website will be added. Concerning climate data, a new tool will also be used, namely LocClim software from FAO, which has been developed to provide and estimate climate conditions for any location on Earth, including those for which no observations are available. The incorporation of these new layers will make it possible to characterize the endemic areas more accurately as well as to delimit the importance of those factors involved in the human and animal fasciolosis transmission risk.

In addition, epidemiological studies will have to reinforce some aspects concerning data collection providing accurate data on snail intermediate hosts, mainly temporal and spatial distribution of Lymnaeid species, resistance and survival of free environmental stages of $F$. hepatica, human and animal infections, including dynamics of prevalences. These three epidemiological aspects will be incorporated as new layers into the GIS project, which allows us to understand fasciolosis transmission along the year and to revalidate existing and/or validate new proposals for GIS forecast models.

All in all, it can be affirmed that GIS is the key in understanding fasciolosis transmission in the Andes.

\section{Acknowledgements}

The research studies concerning GIS models for zoonotic fasciolosis in the South American Andes region were supported by funding from: Project No. 3006 of the Dirección General de Cooperación para el Desarrollo, Generalitat Valenciana, València, Spain, Project No. BOS2002-01978 of the Spanish Ministry of Science and Technology, Madrid, and the Red de Investigación de Centros de Enfermedades Tropicales - RICET (Project No. C03/04 of the Programme of Redes Temáticas de Investigación Cooperativa) of the Fondo de Investigación Sanitaria, Spanish Ministry of Health, Madrid, Spain. A part of this work was supported by 
a grant from University of Valencia (Spain) awarded to the author for a sabbatical study at Louisiana State University.

\section{References}

Alcaíno H, 1990. Epidemiology of fascioliasis in Chile. In: Basic Research in Helminthiasis, Ediciones Logos, Montevideo, 11-30.

Alcaíno H, Vega F, Gorman T, 1993. Epidemiología de la fascioliasis hepática en la VII Región de Chile. Parasitol al Día 17, 99-106.

Apt W, Aguilera X, Vega F, Alcaíno H, Zulantay I, Apt P, González V, Retamal C, Rodríguez J, Sandoval J, 1993. Prevalencia de las fascioliasis en humanos, caballos, cerdos y conejos silvestres en tres Provincias de Chile. Bol of Sanit Panam 115, 405-414.

Bavia ME, Hale LF, Malone JB, Braud DH, Shane SM, 1999. Geographic information systems and the environmental risk of schistosomiasis in Bahia, Brazil. Am J Trop Med Hyg 60, 566-572.

Chen MG, Mott KE, 1990. Progress in assessment of morbidity due to Fasciola hepatica infection: a review of recent literature. Trop Dis Bull 87, R1-R38.

Esteban JG, Flores A, Anglés R, Mas-Coma S, 1999. High endemic of human fascioliasis between Lake Titicaca and La Paz valley, Bolivia. Trans R Soc Trop Med Hyg 93, 151-156.

Fuentes MV, 2004. Proposal of a Geographic Information System for modelling zoonotic fasciolosis transmission in the Andes. Parasitol Lationam 59, 51-55.

Fuentes MV, Malone JB, 1999. Development of a forecast system for fasciolosis in central Chile using remote sensing and climatic data in a Geographic Information System. Res Rev Parasitol 59, 129-134.

Fuentes MV, Malone JB, Mas-Coma S, 2001. Validation of a mapping and prediction model for human fasciolosis transmission in Andean very high altitude endemic areas using remote sensing data. Acta Trop 79, 87-95.

Fuentes MV, Sainz-Elipe S, Nieto, P, Malone JB, Mas-Coma S, 2004. Aplicación de SIG y teledetección satelital en los modleos de transmisión de la fascioliasis humana y animal en los Andes. In: Medio Ambiente, Recursos Nautrales: Análisis mediante Tecnología SIG y Teledetección, vol II, Asociación de Geógrafos Españoles, Universidad de
Murcia, Murcia, 373-386.

Fuentes MV, Sainz-Elipe S, Nieto, P, Malone JB, Mas-Coma S, 2005. Geographical Information Systems risk assessment models for zoonotic fasciolosis in the South American Andes region. Parassitologia 47, 151-156.

Fuentes MV, Valero MA, Nargues MD, Esteban JG, Anglés R, Mas-Coma S, 1999. Análisis of climatic data and forecast indices for human fascioliasis at very high altitude. Ann Trop Med Parasitol 93, 835-850.

Gettinby G, Hope Cawdery MJ, Grainger JNR, 1974. Forecasting the incidence of fascioliasis from climatic data. Int J Biometeorol 18, 319-323.

Knoblock J, Delgado E, Álvarez O, 1985. Human fascioliasis in Cajamarca, Perú. I. Diagnostic methods and treatment with praziquantel. Trop Med Parasitol 36, 88-90.

Leimbacher F, 1978. Experience with the 'Mt' system of forecasting fascioliasis in France. In: Weather and Parasitic Animal Disease. Technical Note No. 159. WMO No. 497, Secretariat of the World Meteorological Organization, Geneva, 6-13.

Malone JB, Abdel-Rahman MS, El-Bahy MM, Huh OK, Shafik M, Bavia ME, 1997. Geographic information systems and the distribution of Schistosoma mansoni in the Nile Delta. Parasitol Today 13, 112-119.

Malone JB, Bergquist NR, Huh OK, Bavia ME, Bernardi M, El Bahy MM, Fuentes MV, Kristensen TK, McCarroll JC, Yilma JM, Zhou XN, 2001. A global network for the control of sanil-borne diseases using satellite surveillance and geographic information systems. Acta Trop 79, 7-12.

Malone JB, Gommes R, Hansen J, Yilma JM, Slingenberg J, Snijders F, Nachtergaele F, Ataman E, 1998. A geographic information system on the potential distribution and abundance of Fasciola hepatica and F. gigantica in east Africa based on Food and Agriculture Organization databases. Vet Parasitol 78, 87-101.

Malone JB, Williams TE, Muller RA, Geaghan JP, Loyacano AF, 1987. Fascioliasis in cattle in Louisiana: development of a system to predict disease risk by climate, using the Thornthwaite water budget. Am J Vet Res 48, 1167-1170. Malone JB, Zukowski SH, 1992. Geographic models and control of cattle liver flukes in the southern USA. Parasitol Today 8, 266-270.

Mas-Coma S, 2005. Epidemiology of fascioliasis in human endemic areas. J Helminthol 79, 207-216. 
Mas-Coma S, Anglés R, Esteban JG, Bargues MD, Buchon P, Franken M, Strauss W, 1999b. The Northern Bolivian Altiplano: a region highly endemic for human fasciolosis. Trop Med Int Health 6, 454-467.

Mas-Coma S, Bargues MD, Valero MA, 2005. Fascioliasis and other plant-borne trematode zoonoses. Int J Parasitol 35, 1255-1278.

Mas-Coma S, Bargues MD, Valero MA, Fuentes MV, 2003. Adaptation capacities of Fasciola hepatica and their relationships with human fascioliasis: from below sea level up to the very high altitude. In: Taxonomy, ecology and evolution of metazoan parasites, vol 2, Presses Universitaires de Perpignan, Perpignan, 81-123.

Mas-Coma S, Esteban JG, Bargues MD, 1999a. Epidemiology of human fasciolosis: a review and proposed new classification. Bull World Health Org 77, 340-346.

Ollerenshaw CB, 1959. The ecology of the liver fluke (Fasciola hepatica). Vet Rec 71, 957-965.

Ollerenshaw CB, 1971a. The influence of climate on the life cycle of Fasciola hepatica in Britain with some observations on the relationship between climate and the incidence of fasciolasis in the Netherlands. In: Facts and Reflections, Symposium Proceedings (3 June 1971), Parasitology Department of the Centraal Diergeneeskundig Institut, Lelystad, 41-63.

Ollerenshaw CB, 1971b. Some observations on the epidemiology of fascioliasis in relation to the timing of molluscicide applications in the control of the disease. Vet Rec 89, 152-162.

Ollerenshaw CB, 1973. A comment on the epidemiology of Fasciola hepatica in Italy. Ann Fac Med Vet Torino 20, 83-121. Ollerenshaw CB, 1974. Forecasting liver-fluke disease. In:
The Effects of Meteorological Factors upon Parasites, Symposium of the British Society for Parasitology. Vol. 12, Blackwell Scientific Publications, Oxford, 33-52.

Ollerenshaw CB, Rowlands WT, 1959. A method of forecasting the incidence of fascioliasis in Anglesey. Vet Rec 71, 591-598.

Ollerenshaw CB, Smith LP, 1969. Meteorological factors and forecasts of helminthic disease. Adv Parasitol 7, 283-232.

Penman HL, 1948. Natural evaporation from open water, bare soil and grass. Proc R Soc London Ser A 193, 120-145.

Ross JG, 1970. The Stormont "wet-day" forecasting system for fascioliasis. Br Vet J 126, 401-408.

Ross JG, 1978. Stormont 'wet-day' fluke forecasting. In: Weather and Parasitic Animal Disease. Technical Note No. 159. WMO No. 497, Secretariat of the World Meteorological Organization, Geneva, 14-20.

Schenome H, Rojas A, 1988. Epidemiología de la fascioliasis animal en Chile. Tendencia de las tasas de infección, por regiones, en cinco especies de mamíferos de consumo beneficiados en mataderos del país. Bol Chil Parasitol 43, 68-70.

Schreiber D, 1981. A comparative examination of threshold values for dry months, taking the situation of Kenya as an example. In: Applied Geography and Development, 17, Institut für wissenschaftliche Zusammenarbeit, Tübingen, 29-45.

Trueba G, Guerrero T, Fornasini M, Casariego I, Zapata S, Ontaneda S, Vasco L, 2000. Detection of Fasciola hepatica infection in a community located in the Ecuadorian Andes. Am J Trop Med Hyg 62, 518.

Walter H, Hgarnickel E, Mueller-Dombois D, 1975. ClimateDiagram-Maps, Springer, Berlin.

Yilma JM, Malone JB, 1998. A geographic information system forecast model for strategic control of fascioliasis in Ethiopia. Vet Parasitol 78, 103-127. 